\title{
Conditioned suppression and enhancement of avoidance in rats: The duration of US
}

\author{
ALBERT E. ROBERTS and ANN G. PORTER \\ Catawba College, Salisbury, North Carolina 28144
}

\begin{abstract}
Rats were trained to leverpress under a free operant avoidance schedule, and signaled response-independent shock (CS-US) was superimposed on avoidance-maintained behavior. Over the experiment, subjects received each of five US durations in a within-subjects Latin squares design: US durations were equal to $(.5 \mathrm{sec})$, shorter than $(.25$ or $.38 \mathrm{sec})$, and greater than $(.75$ or $1 \mathrm{sec})$ avoidable shock. Two subjects initially receiving a short US showed enhanced avoidance during the preshock CS. Subjects initially given a US equal to or longer than avoidable shock showed suppressed avoidance in CS. The control of the CS over avoidance was acquired in the first block of CS-US sessions and was maintained over the experiment irrespective of subsequent changes in US duration.
\end{abstract}

When the effects of signaled response-independent shock (CS-US) on free operant avoidance behavior (Sidman, 1953) is examined, either suppressed or enhanced avoidance may be found during CS, depending upon one of several conditions. One condition is the presence or absence of the US at the end of the CS, following CS-US training. Hurwitz and Roberts (1971) found that, compared to baseline (selected unsignaled periods of a session), a CS controlled suppressed leverpress avoidance when followed consistently by US; on the other hand, the CS controlled enhanced avoidance when the US subsequently was omitted.

The CS also acquires control over enhanced avoidance even when the CS-US association is maintained. One parameter contributing to enhancement control seems to be the intensity of US. Scobie (1972, Experiment 1) examined changes in shuttle-avoidance during CS when the intensity of US was different from avoidable shock. Under .6-mA avoidable shock, CS controlled suppressed avoidance when US was of greater intensity $(1.3 \mathrm{~mA})$; but avoidance enhanced during CS when US was either equal or less intense $(.3 \mathrm{~mA})$. This condition has not been studied with leverpress avoidance.

Another parameter may be the duration of US relative to the duration of avoidable shock. Riess and Farrar (1973), using a .2-sec avoidable shock, found enhanced shuttle-avoidance during CS with the degree of enhancement positively and monotonically related to US durations.

The US duration question has not been studied with a leverpress avoidance baseline, which was the purpose of this experiment. Rat subjects received blocks of sessions under each of five US durations: Two less than,

This research was supported by a grant from the Catawba College Faculty Research Committee. Reprints may be obtained from the first author, Department of Psychology, Catawba College, Salisbury, North Carolina 28144. two greater than, and one equal to the duration of avoidable shock.

\section{METHOD}

Subjects

Five female hooded rats purchased from Blue Spruce Farms, New York, served as subjects. Subjects weighed about $150 \mathrm{~g}$ at the beginning of the experiment and were housed individually with food and water always available.

\section{Apparatus}

A LVE operant chamber (\#143-2), measuring $25 \times 27 \times$ $30 \mathrm{~cm}$ was modified by placing a Chicago miniature lamp assembly in the center of the Plexiglas ceiling. A $3 \times 1 \mathrm{~cm}$ lever extended $2.5 \mathrm{~cm}$ into the right side of the chamber, $4.5 \mathrm{~cm}$ above the grid floor; a deadweight of $20 \mathrm{~g}(.2 \mathrm{~N})$ on the lever operated the microswitch. Other standard assemblies protruding into the chamber were removed. The floor grids consisted of $.25-\mathrm{cm}$ brass rods spaced $1.3 \mathrm{~cm}$ apart parallel to the width of the lever. A BRS shock generator (SG-901) delivered shock via a BRS scrambler (SC-901) to the grids, lever, and metal sides of the chamber. A relay attached to the outside of the chamber side containing the lever was operated at five clicks/second to serve as the CS. The chamber was housed in a soundattenuated box with a blower fan providing ventilation and masking noise $(79 \mathrm{~dB})$. The relay added $2 \mathrm{~dB}$ to the resting noise level when operated. Electromechanical programming and recording equipment was housed in an adjoining room.

\section{Procedure}

Avoidance training. Subjects were trained under a free operant avoidance schedule under which each response postponed shock for $15 \mathrm{sec}$ and briefly $(.2 \mathrm{sec})$ turned off the houselight. In the absence of a response, a .5-sec 1-mA shock was delivered every $5 \mathrm{sec}$. This avoidance schedule was in effect throughout the experiment. All sessions were $2 \mathrm{~h}$, and 20 training sessions were given each subject.

CS-US training. The experiment followed a within-subiect Latin squares design which involved alternating blocks of CS-US sessions with avoidance retraining sessions. Under the CS-US procedure, a 60 -sec clicking CS followed by a $1-\mathrm{mA}$ responseindependent shock (US) was superimposed on avoidancemaintained behavior once every $6 \mathrm{~min}$. The first pairing occurred $6 \mathrm{~min}$ after the beginning of a session. If the subiect received more than six unavoided shocks in the first $2 \mathrm{~min}$, an additional 10 min of "warm-up" was given before the first CS-US pairing. 
Twenty CS-USs were delivered each session, and 10 sessions were given under each US duration. The CS-US procedure was removed for six sessions and then reinstated with a different duration. The CS never occurred without US.

Five US durations were used in the experiment: two less than $(.25$ and $.38 \mathrm{sec})$, two longer than $(.75$ and $1 \mathrm{sec})$, and one equal to $(.5 \mathrm{sec})$ the shock delivered under the avoidance schedule. The order in which US durations were presented each subject was randomized to reduce the possibility of a sequence effect i.e., S1 $(.25,1,5, .75$, and $.38 \mathrm{sec})$, S2 $(.38, .75, .50,1$, and $.25 \mathrm{sec}), \mathrm{S} 3(.5, .25,1, .38$, and .75$), \mathrm{S} 4(.75, .25,1, .38$, and $.5 \mathrm{sec}), \mathrm{S} 5(1, .5, .25, .75$, and $.38 \mathrm{sec})$.

Avoidance measures. Response and shock frequencies were recorded during baseline and CS periods. In this experiment, baseline measures were obtained in the 60 -sec period preceding each CS. For statistical analysis, both mean response and mean shock data for each subject (based on the final four sessions in each block) were converted into ratios (CS mean/baseline mean).

\section{RESULTS}

\section{Avoidance Training}

By the end of training, the avoidance behavior of each subject was stable. Over the final four sessions, the between-subject range in response rate was 14.1 to 17.0 responses per minute; all subjects received less than one unavoided shock per minute.

\section{CS-US Training: Response Measures}

The response ratios obtained for each subject are given in Figure 1 as functions of US duration (Part A) and successive blocks of CS-US sessions (Part B). These ratios were analyzed by a 5 by 5 Latin squares ANOVA (Mendenhall, 1968) with a Neuman-Keuls statistic (Lee, 1975) used for individual comparisons. The differences between subiects seen in Figure 1 were significant $[F(4,12)=51.4, p<.001]$. Specificallv, the ratios of Subjects 1 and 2 were not reliably different, but both were greater than the ratios of Subiects 3 and 5 (ps $<.01)$, which, in turn, were greater than the ratio of S4 (ps <.01). The ratios were affected by a US duration factor $[F(4,12)=7.1, p<.005]$. The $.5-\mathrm{sec}$ US produced greater ratios than under the other four durations (ps <.05). Finally, as Figure 1 (Part B) shows, a "blocks of sessions" factor was present $[F(4,12=17.5$, $\mathrm{p}<.001$ ] . The first block of CS-US sessions produced significantly lower ratios than the other four blocks of sessions $(\mathrm{ps}<.01)$. But following the first block of sessions, the mean ratios remained relatively high (Subjects 1 and 2) or comparable to "no change" levels

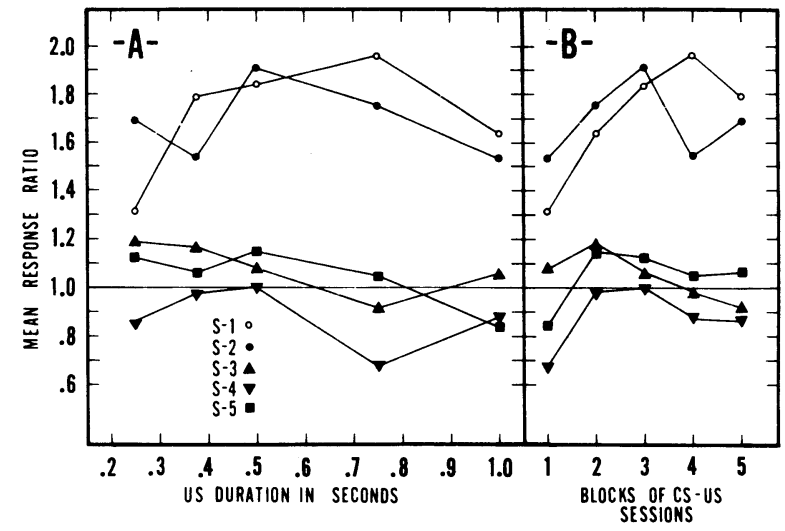

Figure 1. Mean response ratios for each subject as a function of US duration (Part A) and blocks of CS-US sessions (Part B). Values greater than 1.0 indicate that response rate in CS was increased while values less than 1.0 indicate that the response rate was reduced.

(Subjects 3, 4, and 5) over the remainder of the experiment.

\section{CS-US Training: Shock Measures}

Table 1 gives the mean shock rates of the subjects over the experiment, while ratio scores based on small values (e.g., Subjects 1 and 2 ) should be viewed with caution, these data were converted to ratios for statistical analysis. A Latin squares ANOVA indicated significant between-subject differences in shock ratios $[F(4,12)=7.2, p<.005]$. The overall ratios for Subjects 1 and 2 were comparable, and both were less than the ratios of Subjects 3,4 , and 5 (ps $<.01$ ); the ratios of the latter subjects did not differ reliably. We should note that Subjects 1 and 2 typically received their unavoided shocks in the first two or three CS presentations. The ratios were not affected differentially by the US durations $(F<2)$, but were influenced by the "blocks of sessions" factor $[\mathrm{F}(4,12)=5.3, \mathrm{p}<.05]$. The first block of CS-US sessions produced greater ratios, and the second block reduced ratios, both compared to each of the final three blocks of sessions (ps $<.01)$.

\section{DISCUSSION}

The results of the experiment described above can be summarized as follows: (1) The control of the preshock CS over avoidance was related to the duration of US, relative to avoid-

Table 1

Mean Shock Rates for Each Subject Based on the Final Four Sessions of Each Phase of the Experiment

\begin{tabular}{|c|c|c|c|c|c|c|c|c|c|c|c|}
\hline & \multirow{3}{*}{$\begin{array}{c}\text { Avoidance } \\
\text { Training }\end{array}$} & \multicolumn{10}{|c|}{ US Duration (Seconds) } \\
\hline & & \multicolumn{2}{|c|}{.25} & \multicolumn{2}{|c|}{.38} & \multicolumn{2}{|c|}{.50} & \multicolumn{2}{|c|}{.75} & \multicolumn{2}{|c|}{1.0} \\
\hline & & BL & CS & BL & CS & BL & CS & BL & CS & BL & CS \\
\hline S1 & .87 & .35 & .42 & .06 & .08 & .12 & .14 & .19 & .15 & .28 & .24 \\
\hline $\mathbf{S} 2$ & .50 & .10 & .08 & .24 & .24 & .11 & .12 & .17 & .15 & .15 & .16 \\
\hline S3 & .30 & 1.04 & 1.45 & 1.89 & 2.05 & .67 & 1.66 & 1.71 & 2.73 & 1.65 & 2.38 \\
\hline S4 & .79 & .34 & .54 & .56 & .76 & .40 & .73 & .82 & 2.29 & .54 & 1.00 \\
\hline S5 & .72 & .96 & 1.25 & .64 & 1.10 & .67 & 1.05 & 1.01 & 1.73 & .84 & 2.21 \\
\hline
\end{tabular}

Note-Rates are given for baseline (BL) and CS periods. Italics mark the rates from the first block of CS-US sessions. 
able shock; and (2) The control which was acquired by the preshock CS in the first block of sessions then was maintained over the remainder of the experiment, irrespective of changes in US duration.

Turning to the first outcome, when the first CS-US presentations involved a US equal to or longer than (.5, .75 , or $1 \mathrm{sec}$ ) avoidable shock, the CS acquired a suppressive function. In contrast, when the first US was relatively brief $(.25$ or $.38 \mathrm{sec})$, enhancement was found during the CS. We should note that both response and shock data were evaluated in reaching these conclusions. We considered "suppression" to be indicated by a reduction in response rate, or an increase in shock rate (or both) during the CS. For example, viewing only the response ratios of Subjects 3,4 , and 5 might have suggested "no change" in avoidance, or even slight enhancement. But the increased shock rate during CS clearly showed that avoidance responding had reduced ("suppressed") to the point that avoidable shocks were delivered. On the other hand, we viewed "enhancement" as reflecting an increase in response rate during the CS without a corresponding increase in shock rate. A shock rate less than baseline might be anticipated unless the baseline rate were so low to preclude further reductions.

On the second outcome, the CS developed either the enhancement or suppressive function in the first block of CS-US sessions, and both functions were surprisingly insensitive to changes in US duration. The degree of enhancement was not attenuated, and often increased, when US duration was increased (Subjects 1 and 2). The degree of suppression lessened after the first block of sessions, but suppression was maintained throughout the experiment (Subjects 3, 4, and 5).

Finally, a positive and monotonic relationship between avoidance change during CS and US duration (cf. Riess \& Farrar, 1973) was not observed. The presence of the avoidance baseline during, or the US following, our CS probes could account for this difference between results. These data do extend the results of Scobie (1972) to include duration differences between US and avoidable shock, at least in the initial block of CS-US sessions. That is, when US is greater than avoidable shock on some dimension (intensity, duration), suppression seems to result. Enhancement develops when US is less than avoidable shock on either an intensity or duration dimension. But in contrast to the Scobie (1972) experiments, we found suppressed avoidance when US and avoidable shock were identical.

\section{REFERENCES}

Hurwitz, H. M. B., \& Roberts, A. E. Conditioned suppression of an avoidance response. Journal of the Experimental Analysis of Behavior, 1971, 16, 278-281.

LEE, W. Experimental design and analysis. San Francisco: Freeman, 1975. Pp. 302-304.

Mendenhall, $\mathrm{W}$. The design and analysis of experiments. Belmont, Calif: Wadsworth, 1968. Pp. 189-192.

Riess, D., \& FARRAR, C. H. UCS duration, conditioned acceleration, multiple CR measurement, and Pavlovian R-R laws. Journal of Comparative and Physiological Psychology, 1973, 82, 144-151.

ScobIE, S. R. Interaction of an aversive Pavlovian conditional stimulus with aversively and appetitively motivated operants in rats. Journal of Comparative and Physiological Psychology, 1972. 79, 171-188.

Sidman, M. Avoidance conditioning with brief shock and no exteroceptive warning signal. Science, 1953, 118, 157-158.

(Received for publication September 3, 1976.) 